This item was submitted to Loughborough's Research Repository by the author.

Items in Figshare are protected by copyright, with all rights reserved, unless otherwise indicated.

\title{
Machinability of natural-fibre-reinforced polymer composites: Conventional vs ultrasonically-assisted machining
}

PLEASE CITE THE PUBLISHED VERSION

https://doi.org/10.1016/j.compositesa.2019.01.028

\section{PUBLISHER}

(C) Elsevier BV

\section{VERSION}

AM (Accepted Manuscript)

\section{PUBLISHER STATEMENT}

This paper was accepted for publication in the journal Composites Part A: Applied Science and Manufacturing and the definitive published version is available at https://doi.org/10.1016/j.compositesa.2019.01.028.

\section{LICENCE}

CC BY-NC-ND 4.0

\section{REPOSITORY RECORD}

Wang, Dong, P.Y. Onawumi, S.O. Ismail, H.N. Dhakal, I. Popov, Vadim Silberschmidt, and Anish Roy. 2019. "Machinability of Natural-fibre-reinforced Polymer Composites: Conventional Vs Ultrasonically-assisted Machining". figshare. https://hdl.handle.net/2134/36865. 


\title{
Machinability of natural-fibre-reinforced polymer composites: Conventional vs ultrasonically-assisted machining
}

\author{
D Wang ${ }^{\text {a }}$, PY Onawumi ${ }^{\text {a }}$, SO Ismail ${ }^{\mathrm{b}}$, HN Dhakal $^{\mathrm{b}}$, I Popov ${ }^{\mathrm{b}}$, VV Silberschmidt ${ }^{\mathrm{a}}$, A Roy $^{\mathrm{a}^{*}}$ \\ ${ }^{a}$ Wolfson School of Mechanical, Electrical and Manufacturing Engineering, Loughborough \\ University, Loughborough, LE11 3TU, United Kingdom \\ ${ }^{\mathrm{b}}$ School of Engineering, Faculty of Technology, University of Portsmouth, Portsmouth,
} PO1 3DJ, United Kingdom

*Corresponding author: Email: A.Roy3@lboro.ac.uk (A. Roy), Tel.: +44(0) 1509227637

\begin{abstract}
Natural-fibre-reinforced polymer (NFRP) composites are becoming a viable alternative to synthetic fibre based composites in many industrial applications. Machining is often necessary to facilitate assembly of parts in a final product. This study focuses on a comparative experimental analysis of the effects of conventional drilling (CD) and a hybrid ultrasonically-assisted drilling (UAD) of a hemp fibre-reinforced vinyl ester composite laminate. The results obtained indicate that $\mathrm{UAD}$ is more efficient when compared to $\mathrm{CD}$ for a range of drilling conditions. It yields lower cutting forces and energy resulting in reduced machining-induced damage in the composite, including diminished burr formation and fibre pull-outs. The holes drilled with UAD exhibit improved surface finish and hole quality when compared to those produced with CD. The study demonstrates the applicability of UAD as a viable machining process for improved machinability of heterogeneous NFRP composite materials.
\end{abstract}

Keywords: A. Natural fibers; D. Optical microscopy; E. Machining. 


\section{Introduction}

In recent years, a demand for natural-fibre-reinforced polymer (NFRP) composites has increased steadily. NFRPs are ideally suited for applications in secondary or tertiary structures such as automotive panels, packaging applications, and others where the demand for advanced mechanical properties is less important. This demand is primarily driven by a need to reuse and recycle composites at their end-of-life [1]. Fibre-reinforced plastics reinforced with glass or carbon fibres are notoriously difficult to recycle, to such an extent that their direct disposal in a landfill or incineration is preferred [2]. To mitigate these problems, the use of so-called 'ecocomposites' with a lower environmental impact became important.

NFRPs have several advantages: first, the use of natural organic materials in replacement for traditional mineral (inorganic) ones allow for a considerable reduction in the use of nonbiodegradable materials from non-renewable resources. Fibres in NFRPs are usually drawn from relatively abundant plants, making them economically viable and environmentally sustainable. Production processes involved in the manufacturing of NFRPs are less dangerous and pose a lower risk to personnel handling the material (in contrast, carbon fibres/fillers pose a risk of inhalation during their manufacture). Additionally, NFRPs can be engineered to possess beneficial properties such as thermal and acoustic insulation and lower specific weight in comparison to their mineral-filled counterparts [3]. Among natural fibres, hemp fibre is relatively cheap to produce and process; it is readily available in Europe and Asia in large quantities. It is classified as one of the high lignocellulosic fibres, with good mechanical properties, making it an ideal reinforcement for many fibrous composites [4-14].

To facilitate assembly of functional components, machining of NFRP composites is unavoidable in many cases. Drilling is of particular interest as holes need to be machined for 
bolts or rivets. This machining process is known to induce various modes of damage in the machined composite parts such as delamination, fibre pull-outs and inter-laminar crack propagation resulting i.a. in hole-roundness errors. Several factors contribute to the extent of drilling-induced damage in composite materials, including cutting parameters and geometry of the tool used in machining. A common aspect is the need to reduce machining forces as a way to diminish drilling-induced damage [15]. Some limited studies in the drilling of hemp-fibre composites exist; typically, they recommend a low feed rate and a high cutting speed to reduce delamination $[16,17]$. Some studies into hemp-fibre-reinforced vinyl-ester (HF/VE) composites showed that machining parameters and aspect ratio of fibres affected machining-induced damage [17]. From an industrial perspective, there is a clear need to improve the machining processes to yield damage-free components, for which a fundamentally new approach of using hybrid machining is required. Ultrasonically assisted drilling (UAD) is one such hybrid machining process, in which high-frequency low-amplitude vibration is superimposed on drill-bit movement during the cutting process. Prior experimental studies in aerospace-grade carbon/epoxy composites showed a significant reduction in thrust force - up to $30 \%$ and more with a concomitant improvement in hole quality and surface topography $[18,19,20]$.

In this paper, machinability of HF/VE NFRP composites is studied using both conventional and ultrasonically assisted drilling. The paper is organised as follows: in Section 2, descriptions of the experimental setup (including various characterisation instruments used) is presented along with details of workpiece material and cutting tools. Section 3 comprises measurement results and associated discussion. The paper ends with some concluding remarks in Section 4. 


\section{Experimental work}

\subsection{Materials specification}

In this study, hemp-fibre-reinforced vinyl-ester composite plates with dimensions $140 \mathrm{~mm} \times 140$ $\mathrm{mm} \times 4 \mathrm{~mm}$ were used as workpiece material. The aspect ratio and volume fraction of the fibre were 19 and $26 \%$, respectively, with a nominal fibre length of $432 \mu \mathrm{m}$ and its nominal diameter of $22.4 \mu \mathrm{m}$. The choice of this fibre aspect ratio was based on prior machining studies that showed reduced delamination in conventional drilling [17]. Each composite plate was made of 4 layers of needle punched non-woven hemp mat with randomly-oriented hemp fibres, fabric weight $330 \mathrm{~g} / \mathrm{m}^{2}$ with a volume fraction of 0.26 . The void content recorded was approximately 4\%. A combination of hand lay-up and compression moulding was used to prepare the HF/VE composite samples. Non-woven mat was first dried at $100^{\circ} \mathrm{C}$ to remove storage moisture. A measured quantity of vinyl ester resin was mixed with a catalyst (MEKP) for rapid curing/crosslinking. The followed detailed manufacturing process was similar to that described in Dhakal et al. [21]. The VE matrix had a specific density of $1.04 \mathrm{~g} / \mathrm{ml}$ and a flash point of $23-29^{\circ} \mathrm{C}(74-$ $\left.84^{\circ} \mathrm{F}\right)$. The composite lay-up was subjected to a pressure of $1 \mathrm{MPa}$ for 1.5 hours and left for 24 hours at room temperature for curing. Subsequently, the samples were post-cured for 4 hours at $80^{\circ} \mathrm{C}$, using a standard oven. These parameters were optimised in a preliminary study. Thermogravimetric results obtained (Fig. 1) depict a thermal-decomposition process of the HF/VE composite. TGA was performed using a TGA Q $50 \mathrm{~V}$ from TA Instruments. The initial weights of the samples were approximately $8 \mathrm{mg}$. The samples were heated in a nitrogen filed environment at the heating rate of $20{ }^{\circ} \mathrm{C} / \mathrm{min}$ from ambient temperature to $550{ }^{\circ} \mathrm{C}$. No significant reduction in weight of the sample was observed below $\sim 300^{\circ} \mathrm{C}$, after which the composite started to degrade. The produced composite had the following mechanical properties: the flexural 
modulus and strength were in the range 4.70-4.90 $\mathrm{GPa}$ and 91-110 $\mathrm{MPa}$, respectively; these parameters for tension were 5.3-7.4 GPa and 64-80 MPa and modulus, respectively.

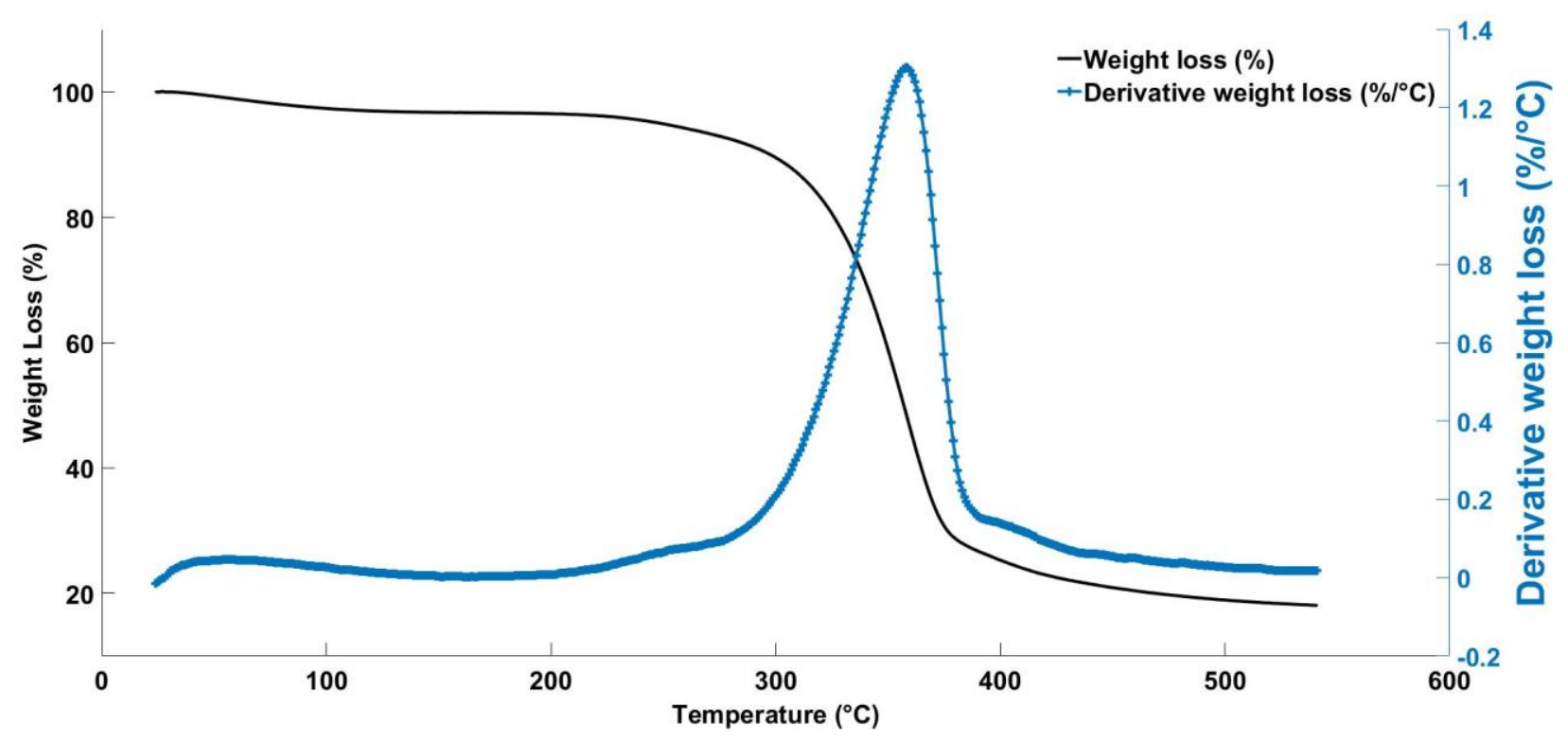

Fig. 1 Thermo-gravimetric analysis of decomposition of HF/VE composite with temperature.

\subsection{Experimental setup}

Machining experiments were conducted on a universal Harrison M-300 lathe machine with a maximum spindle speed of $2500 \mathrm{rpm}$. The lathe was appropriately modified to integrate a Langevin-type piezoelectric transducer with a maximum power rating of $106.6 \mathrm{~W}$. The transducer consists of piezoelectric ceramics rings, a backing mass, a front mass, a horn and a pre-stressed central bolt; it produced mechanical vibration by converting electric energy based on a piezoelectric effect. The vibration generated by the piezoelectric transducer was such that, effectively, an axial vibration was superimposed on a rotating drill bit. A high-speed-steel (HSS) two-flute $\varnothing 3 \mathrm{~mm}$ Jobber carbide twist drill, with a point and helix angles of $135^{\circ}$ and $28^{\circ}$, respectively, with strengthened web thickness (Fig. 2(b)) was used for the drilling experiments, 
Prior studies in drilling of carbon/epoxy composites showed that a TiN coated HSS drilling tool was ideal as it helped to reduce tool wear $[19,22]$ which is an important factor when drilling composite material. Details of the drill used are listed in Table 1.

A Kistler 9345b piezoelectric two-component dynamometer was placed on the cross slide of the lathe, fixed on an angle plate to measure thrust force and torque in the process of drilling. The dynamometer is capable of force and torque measurement up to $10 \mathrm{kN}$ and $25 \mathrm{Nm}$, respectively. The force and torque data measured by the dynamometer were obtained using charge amplifiers, by converting and transmitting the data through an analogue-digital converter (digital oscilloscope Picoscope) connected to a computer. The acquired data in digital format were further processed using Matlab ${ }^{\mathrm{TM}}$.

Temperature measurements were performed with an infrared camera (MICRO-EPSILON thermoImager TIM 400) during the drilling process in real time. The thermal camera was calibrated using a K-type thermocouple to ensure the accuracy of measurements, considering the workpiece material and ambient lighting conditions. The camera was positioned to focus on an area at the point of contact between the tool and the workpiece at the entry surface. The emissivity of the workpiece and the drill bit were evaluated to be 0.29 and 0.27 , respectively, which were set in the software. Details of the thermal imaging system are listed in Table 2. A cooling system consisting of a cold-air gun vortex tube, a pressure regulator, a gauge meter and a compressor was used to cool the machined area. 


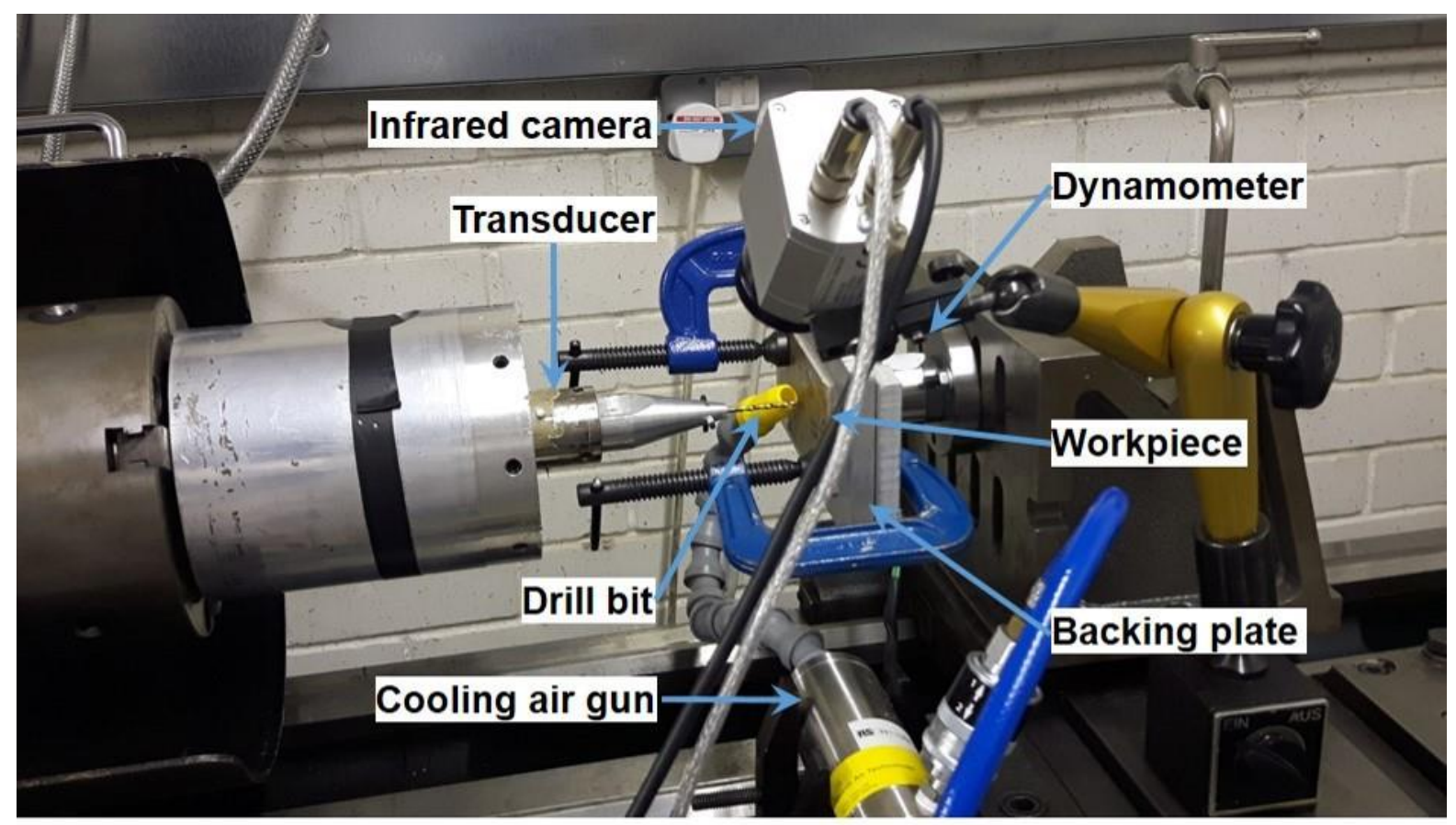

(a)

(b)

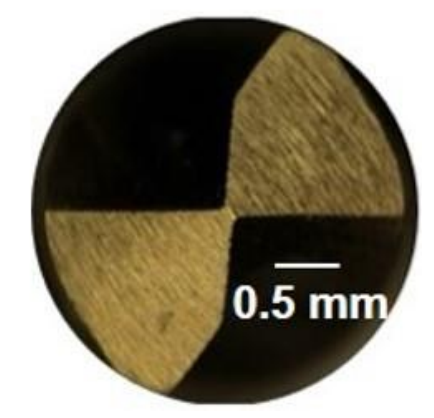

Fig. 2 (a) Experimental set-up; (b) HSS TiN 3 mm Jobber carbide twist drill

Table 1 Drill properties

\begin{tabular}{lcc}
\hline Parameter & Unit & Value \\
\hline No. of flutes & $\circ$ & 2 \\
Point angle & $\circ$ & 135 \\
Point angle & $\circ$ & 135 \\
Helix angle & $\circ$ & 28 \\
Chisel edge angle & $\circ$ & 112 \\
Chisel edge length & $\mathrm{mm}$ & 0.14 \\
Land & $\mathrm{mm}$ & 0.4 \\
Flute length & $\mathrm{mm}$ & 33 \\
Cutting-edge length & $\mathrm{mm}$ & 1.4 \\
Web thickness & $\mathrm{mm}$ & 0.1 (Strengthened) \\
\hline
\end{tabular}


Table 2 Specification of the infrared camera

\begin{tabular}{cc}
\hline Model & TIM 400 \\
\hline Optical resolution & $382 \times 288$ pixels \\
Temperature range & $0-250^{\circ} \mathrm{C}$ \\
Spectral range & 7.5 to $13 \mu \mathrm{m}$ \\
Image frequency & $80 \mathrm{~Hz}$ \\
Thermal sensitivity & $80 \mathrm{mK}$ \\
Accuracy & $\pm 2^{\circ} \mathrm{Cor} \pm 2 \%$ \\
\hline
\end{tabular}

\subsection{Measurement of vibration amplitude}

A vibration amplitude of the tooltip in UAD was measured using a Polytec ${ }^{\mathrm{TM}}$ laser vibrometer (OFV-3001), capable of measuring vibration at a velocity up to $10 \mathrm{~m} / \mathrm{s}$ with a resolution of $0.08 \mu \mathrm{m} / \mathrm{s}$. This process was employed to tune the frequency and the amplitude of the drill tip in free vibration. For UAD, the system was tuned at $37.9 \mathrm{kHz}$ with the vibration amplitude of $32.3 \mu \mathrm{m}$ peak-to-peak.

\subsection{Experimental methodology}

Drilling tests were carried out using a constant feed at $0.03 \mathrm{~mm} / \mathrm{rev}$ and five spindle speeds - 85, 370, 540, 800 and $1200 \mathrm{rpm}$. CD tests were carried out first, followed by UAD. This was repeated three times for each machining condition, to ensure accuracy and repeatability of experimental results. Drill bits were changed after completion of tests for each feed rate to ensure that tool wear did not affect results. To reduce the drilling-induced damage, the HF/VE samples were supported with a pre-drilled aluminium backing plate (Fig. 2 a).

\subsection{Damage characterisation and hole quality}

Damage in the composite caused by drilling was observed, measured and assessed using light microscopy. Alicona InfiniteFocus microscope with a magnification of $2.5 \times$ was used with a field of view $\mathrm{X}$ and $\mathrm{Y}$ at $5716 \mu \mathrm{m}$ and $4351 \mu \mathrm{m}$, respectively. Next, surface topographies of the 
exit surface of drilled holes were studied by employing TalyMap 4.0 software, which provides the contour plots with spikes illustrating fibre pull-outs. To assess hole quality, a coordinate measuring machine (CMM) (Metris LK Ultra 627134) with an SP25 analogue scanning probe and a $\varnothing 1 \mathrm{~mm}$ stylus was used to measure diameter and circularity of the drilled holes. These parameters were obtained for depths of $0.5 \mathrm{~mm}, 2 \mathrm{~mm}$ and $3 \mathrm{~mm}$ from the drill-entry surface.

\section{Results and discussion}

\subsection{Cutting forces and energy}

Cutting forces (thrust force and torque) imposed by the tool on the HF/VE composite were recorded in real time for different machining parameters. A typical experimental result demonstrates a noticeable reduction of the thrust force and the torque in UAD when compared to $\mathrm{CD}$, as depicted in Fig. 3. The process can be divided into four main stages. Stage 1 corresponds to the initial drill contact with the workpiece. Stages 2 and 3 indicate the onsets of full drill engagement and exit, respectively. While Stage 4 represents full drill penetration. For CD, the thrust force gradually increased with time after the initial engagement. When the drill tip was fully engaged with the workpiece (Stage 2), the force reached a plateau with minor oscillations recorded due to the inherent heterogeneity of the composite material, vibrations in the drilling equipment and high sensitivity of the measurement system. When the drill bit fully penetrated the workpiece, the force reduced to zero. As expected the force was observed to increase from Stage 1 to Stage 2 with the increasing tool tip engagement. Beyond Stage 2 the forces were somewhat stabilised (in CD) until Stage 3 when the tool started to exit the workpiece. We observe a larger temporal duration corresponding to the drill exit (Stage 3 to Stage 4), which was partially responsible for fibre push-out. 


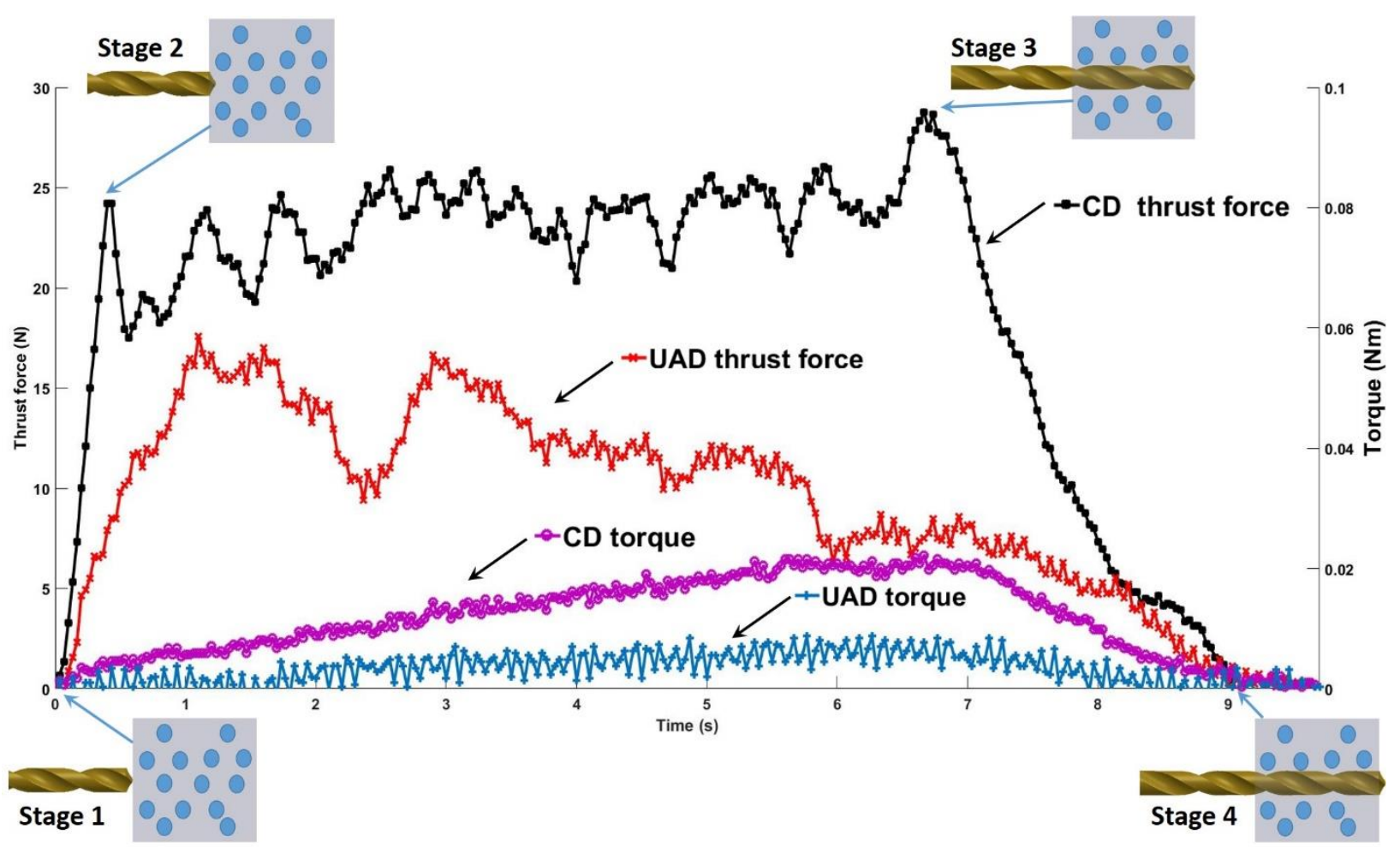

Fig. 3. Evolution of thrust force and torque in HF/VE drilling at a feed rate of $36 \mathrm{~mm} / \mathrm{min}$

The maximum levels of thrust force and torque during the period of complete engagement of the drill bit are reported in Fig. 4 for the five sets of feed rates (calculated as spindle speed $\times$ feed per revolution). For the range of feed rates studied, UAD shows reductions in excess of $20 \%$ and $30 \%$ in the level of thrust force and torque, respectively. These reductions for the studied range of drilling parameters can be as high as $56 \%$ and $74 \%$, respectively (see all relevant data in Table 3). Generally, the net reduction of machining forces (when compared to conventional machining) decreased with an increase in the feed rate (Fig. 4), which is attributed to a decrease in the intermittent nature of the ultrasonic cutting process. The CD cutting forces were observed to be higher for $36 \mathrm{~mm} / \mathrm{min}$ than that of $24 \mathrm{~mm} / \mathrm{min}$. The wider variation in the recorded averages indicates an unstable machine regime, which ultimately resulted in poor 
drilling quality. Overall, the transition to UAD showed improvements in reducing machining forces.

A critical machining parameter indicating the effectiveness of the drilling process is energy $(E)$ required to drill a hole. This can be evaluated from the thrust force and torque with the following expression:

$$
E=\int_{0}^{l} F d l+2 \pi \int_{0}^{l} \frac{T}{f} d l,
$$

where $F$ is the thrust force, $T$ is the torque, $f$ is the feed per revolution and $l$ is the thickness of the drilled workpiece [23]. The data calculated with Eq. 1 revealed that $E$ was dominated by the contribution from the torque in both studied drilling processes. As an example, for a feed rate of $36 \mathrm{~mm} / \mathrm{min}$, the energy required in $\mathrm{CD}$ was $14.3 \mathrm{~J}$ with the torque component contributing $99.3 \%$ to it. While in UAD, the drilling energy was $3.9 \mathrm{~J}$ with the torque contributing $98.6 \%$ to the net energy. Our studies indicate that with the hybrid machining process there is a nominal reduction in excess of $50 \%$ and up to $84 \%$ in drilling energy spent using UAD in producing holes in the HF/VE composite. The energy expenditure for all feed rates studied is presented in Table 4. 


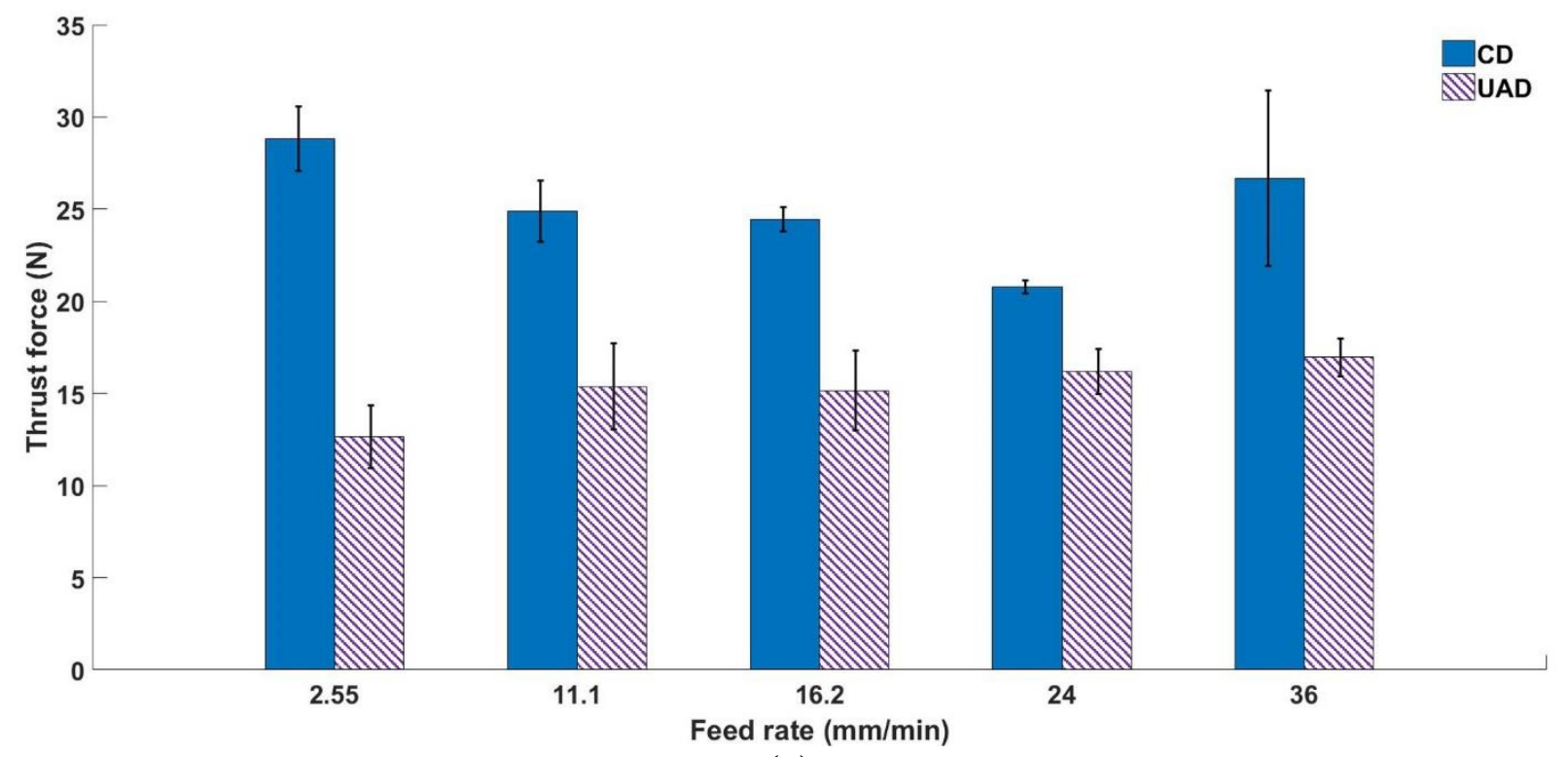

(a)

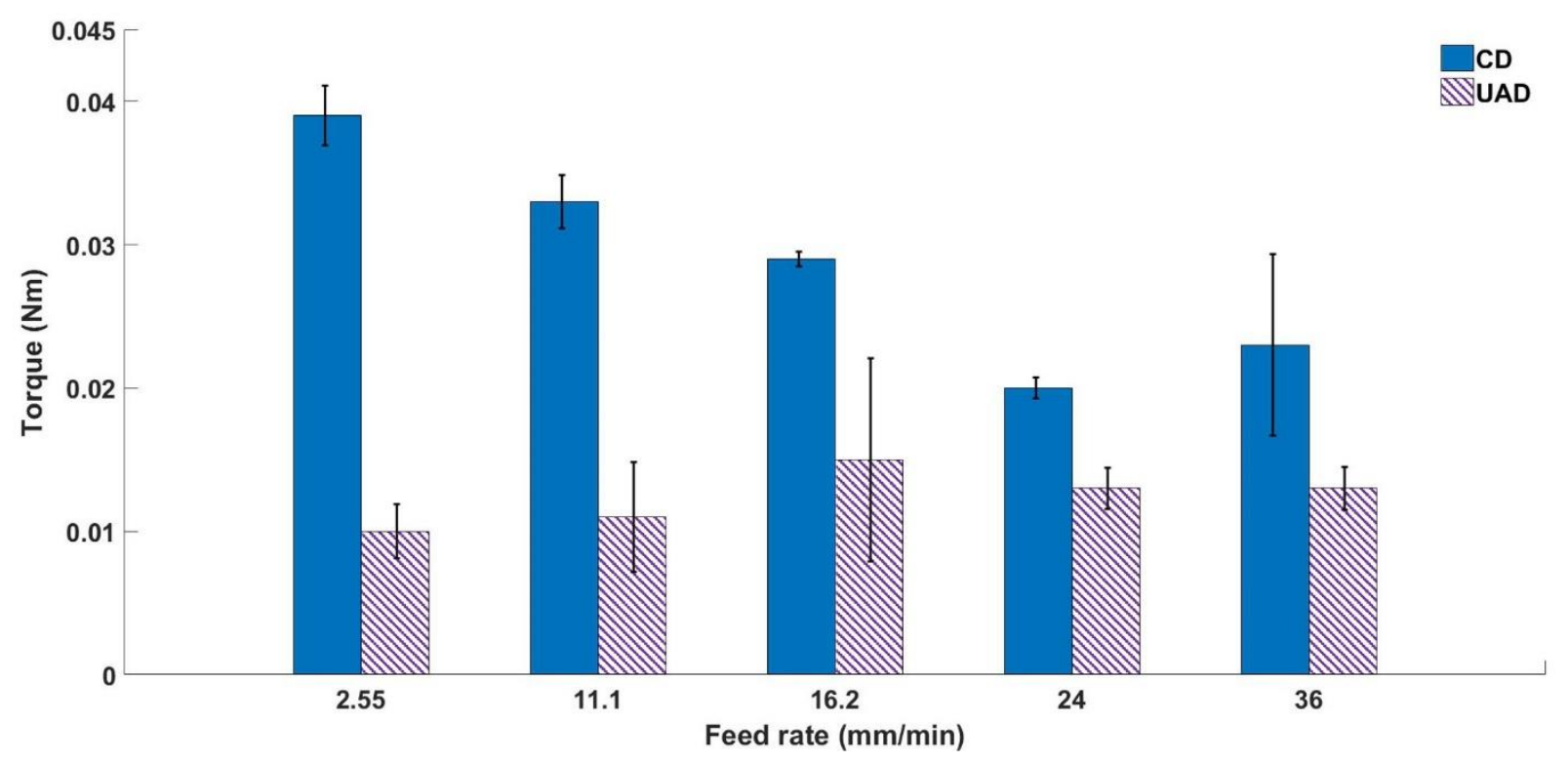

(b)

Fig. 4. Comparison of maximum cutting forces thrust (a) and torque (b) for UAD and CD, with the error bars indicating standard deviation of results. 
Table 3 Maximum cutting forces (with a reduction for UAD when compared to CD)

\begin{tabular}{ccccccc}
\hline $\begin{array}{c}\text { Feed rate } \\
\text { (mm/min) }\end{array}$ & \multicolumn{2}{c}{ Thrust Force (N) } & Average Force & \multicolumn{2}{c}{ Torque $(\mathbf{N m})$} & Average Torque \\
\hline 2.55 & 28.82 & 12.65 & $56 \%$ & 0.039 & 0.010 & $74 \%$ \\
11.1 & 24.89 & 15.38 & $38 \%$ & 0.033 & 0.011 & $67 \%$ \\
16.2 & 24.45 & 15.16 & $38 \%$ & 0.029 & 0.015 & $48 \%$ \\
24 & 20.78 & 16.18 & $22 \%$ & 0.020 & 0.013 & $35 \%$ \\
36 & 26.67 & 16.96 & $36 \%$ & 0.023 & 0.013 & $43 \%$ \\
\hline
\end{tabular}

Table 4 Reduction of cutting energy in UAD when compared to CD

\begin{tabular}{cccc}
\hline $\begin{array}{c}\text { Feed rate } \\
(\mathbf{m m} / \mathbf{m i n})\end{array}$ & CD & UAD & $\begin{array}{c}\text { Energy } \\
\text { reduction }\end{array}$ \\
\hline 2.55 & 20.3 & 3.2 & $84 \%$ \\
\hline 11.1 & 22.0 & 3.9 & $82 \%$ \\
\hline 16.2 & 13.6 & 6.6 & $51 \%$ \\
\hline 24 & 16.3 & 6.7 & $59 \%$ \\
\hline 36 & 14.3 & 3.9 & $73 \%$ \\
\hline
\end{tabular}

\subsection{Hole quality}

The purpose of any drilling process is to ensure acceptable quality of produced holes. Hence, analysis of cutting forces was accompanied by an assessment of finish quality including an analysis of drilling-induced damage in the composite for the two studied techniques.

A reduction in cutting forces typically leads to reduced machining-induced damage. An assessment of such damage was carried out for holes drilled using UAD and CD. Observations were made with light microscopy, and the obtained results are shown in Figs. 5 a-d; this was followed by a surface topography scan of the drilled specimens (Figs. 5 c-d). Burr formation was reduced in UAD, which was observed from the images taken at both entry and exit surfaces. The results show that $\mathrm{CD}$ induced more exit-hole damage with fibre push-outs at the surface having more perturbations in comparison to UAD. Fibre push-outs at the exit side in $\mathrm{CD}$ were greater than that in UAD, showing larger permanent deformation of the ply. Thus, UAD incurred 
significantly lower visible damage in the ply. This could be also attributed to the non-woven hemp mat used as reinforcement and a combination of hand lay-up and compression moulding used in the manufacturing process of the composite. A similar observation was reported in an experimental and analytical study of the effect of the manufacturing process on drilled hole quality of glass fibre [24].

Hole quality was assessed in $\mathrm{UAD}$ and $\mathrm{CD}$ for various feed rates and is summarised in Fig. 6. First, the nominal hole diameter in UAD was observed to be closer to the drill-bit diameter of $3 \mathrm{~mm}$ than that in CD. UAD at a feed rate of $16.2 \mathrm{~mm} / \mathrm{min}$ and $24 \mathrm{~mm} / \mathrm{min}$ yield the best results with regard to the hole diameter. The hole circularity was also assessed; it is defined by evaluating the maximum-peak $(P)$ and -valley $(V)$ deviation of the drilled hole from a circle. Thus a circularity of 0 indicates a perfect circle. From Fig. 6 b, it can be observed that the circularity in UAD when compared to CD did not improve at lower feed rates- from 2.55 to 16.2 $\mathrm{mm} / \mathrm{min}$. However, with an increase in the feed rate, improvement in the nominal circularity was observed in UAD. It was noted that improvement in circularity was not always consistently observed in UAD (due to wide statistical scatter); however, it has the potential to demonstrate advantage at feed rates beyond a critical value. Thus, from our study, a feed rate of $24 \mathrm{~mm} / \mathrm{min}$ yielded a favourable result in terms of circularity and hole diameter. 
CD

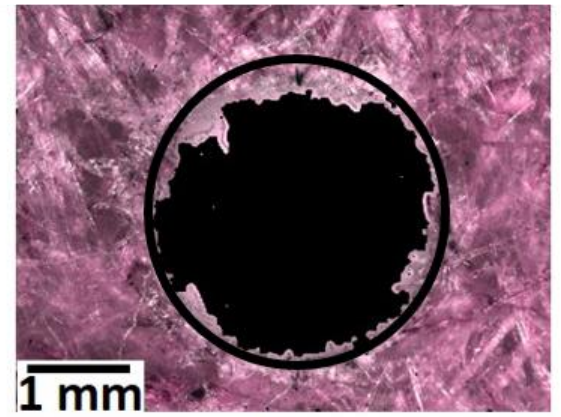

(a)

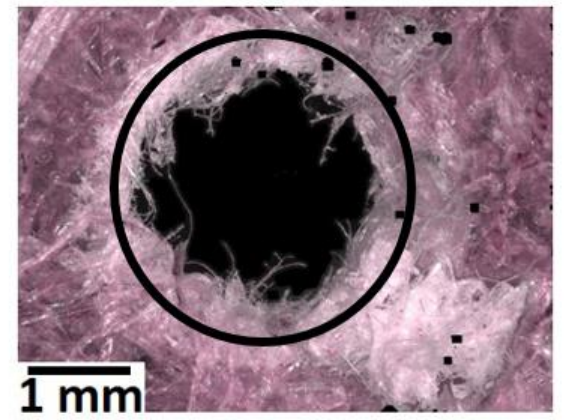

(c)

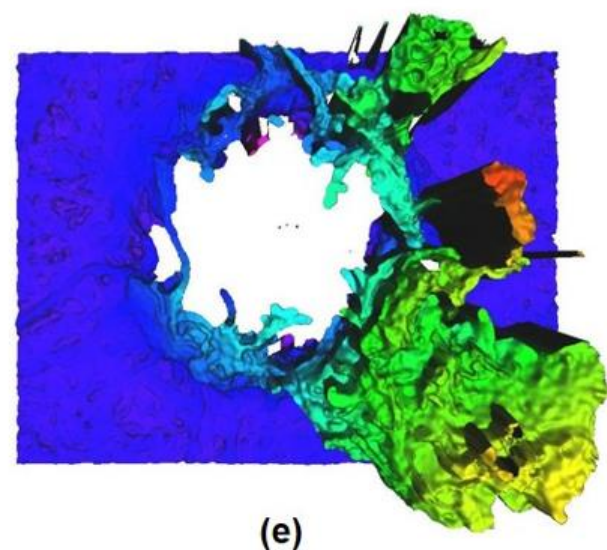

UAD

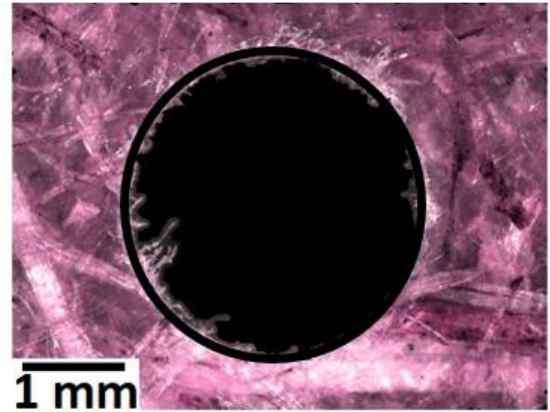

(b)

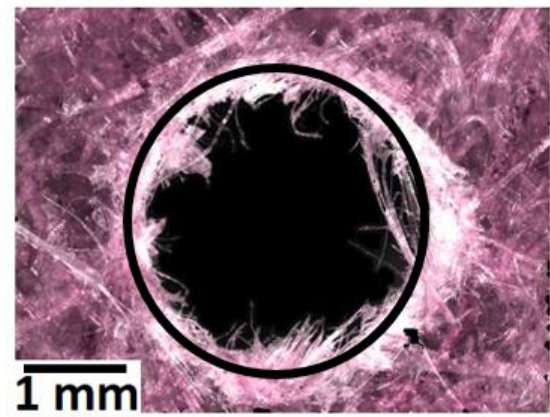

(d)

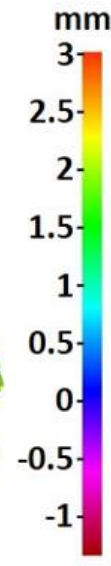

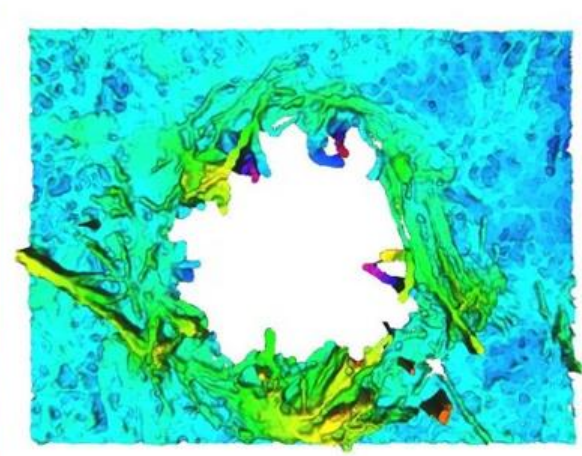

(f)

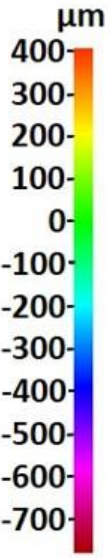

Fig. 5. Light microscopy image of holes for CD at entry (a), UAD at entry (b), CD at exit (c), UAD at exit (d) and surface scans with fibre push-out and burrs for CD (e) and UAD (f) after drilling process at feed rate of $36 \mathrm{~mm} / \mathrm{min}$. A black circle corresponding to the drill diameter is sketched in (a)-(d) for clarity. 


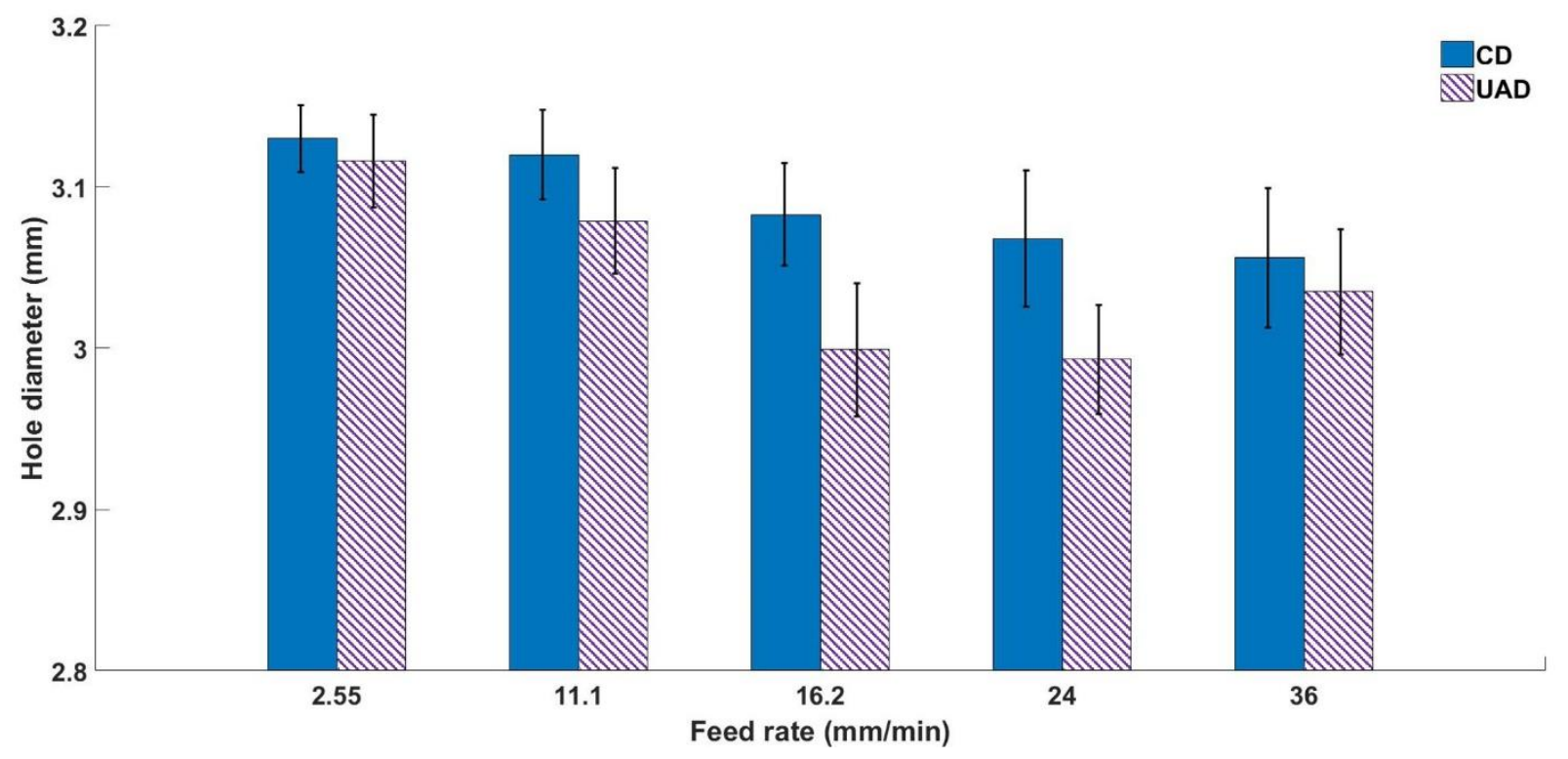

(a)

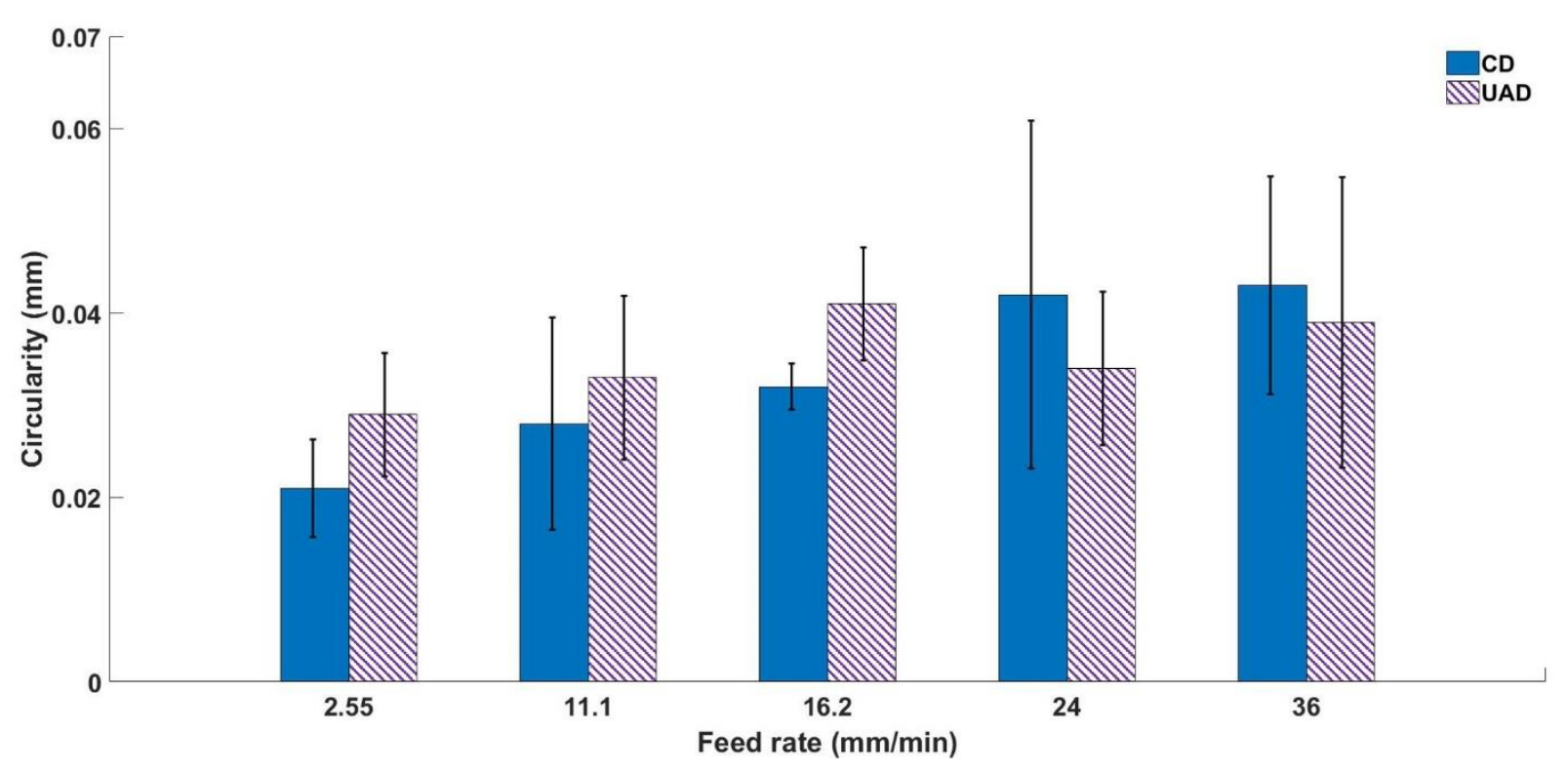

(b)

Fig. 6. Hole diameter (a) and circularity (b) in UAD and CD at varied feed rates, with the error bars indicating standard deviation of results. 


\subsection{Thermal results}

Temperatures in a process zone during the drilling process were captured with an infrared thermal camera (Fig. 7) for the machining condition with air cooling. Maximum temperatures that were recorded are listed in Table 5. Some key observations can be made from the experiments. First, UAD generated more heat in the process zone when compared to CD. This is primarily due to the process of repetitive impacts at the tool-workpiece interface in UAD, which inevitably led to a temperature rise in the process zone caused by increased friction and plastic work at the interface. This phenomenon was also observed in the ultrasonically assisted turning of metals [25]. In the lower range of feed rates, the temperature was observed to rise in $\mathrm{CD}$ and UAD with an increase in drilling feed rate. In $\mathrm{CD}$, the maximum temperature was observed to increase from room temperature to $44^{\circ} \mathrm{C}$ when the feed rate increased from 2.55 $\mathrm{mm} / \mathrm{min}$ to $36 \mathrm{~mm} / \mathrm{min}$. In UAD, the temperature increased from $71^{\circ} \mathrm{C}$ to $94^{\circ} \mathrm{C}$ with an increase in feed rates from $2.55 \mathrm{~mm} / \mathrm{min}$ to $24 \mathrm{~mm} / \mathrm{min}$. However, at higher feeds, the nominal temperature measured at the entry face was observed to reduce. The main reason for this observation was a shorter engagement time of the drill bit with the workpiece material; as a result, the higher temperature at the drill exit face did not have sufficient time to conduct to the front face (where measurements were made). This implies that a critical feed rate exists, beyond which the nominal temperature decreases. This phenomenon was also observed in the drilling of bone with ultrasonic assistance [26].

An important point with regard to the temperatures recorded in UAD was that it was well below the degradation temperature (Fig. 1); therefore, thermal decomposition was not the cause for force reduction in UAD. 


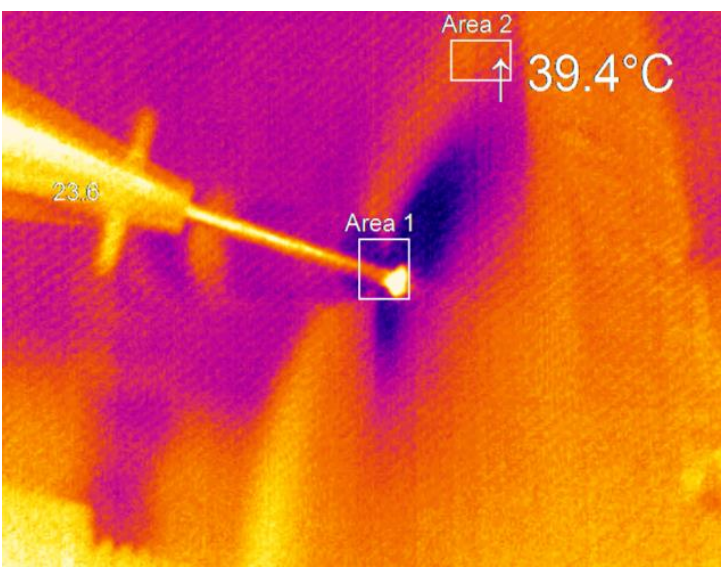

(a)

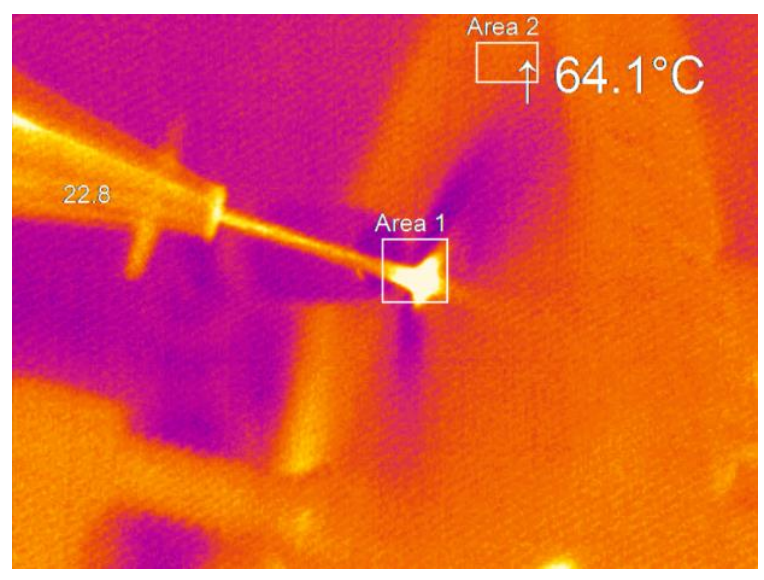

(b)

Fig. 7. Snapshots with an infra-red camera for CD (a) and UAD (b) at $36 \mathrm{~mm} / \mathrm{min}$ with cooling

Table 5 Maximum cutting temperature at various feed rates in CD and UAD.

\begin{tabular}{cccc}
\hline $\begin{array}{c}\text { Feed rate } \\
(\mathbf{m m} / \mathbf{m i n})\end{array}$ & $\begin{array}{c}\text { Engagement Time } \\
(\mathbf{s})\end{array}$ & \multicolumn{2}{c}{ Maximum Temperature $\left({ }^{\circ} \mathrm{C}\right)$} \\
\hline 2.55 & 94.1 & $\mathrm{CD}$ & UAD \\
11.1 & 21.6 & $\mathrm{RT}^{*}$ & 71 \\
16.2 & 14.8 & 37.9 & 82.7 \\
24 & 10 & 39.8 & 90.4 \\
36 & 6.7 & 44 & 94 \\
51 & 4.7 & 43.3 & 65 \\
\hline \multicolumn{3}{c}{}
\end{tabular}

\section{Concluding remarks}

In this paper, a hybrid dry machining process - ultrasonically-assisted drilling - was used to demonstrate improvements in machining of the HF/VE NFRP composite material. Based on the results obtained, the following conclusions were drawn:

- A significant reduction in cutting forces and energy was observed in UAD when compared to $\mathrm{CD}$ of such materials. 
- Quality of holes drilled with UAD was better in terms of both hole diameter and circularity.

- Drilling-induced damage in the composite decreased in UAD.

- The temperature in the process zone in UAD was higher than that in $\mathrm{CD}$; however, the measured temperature was significantly lower than the temperature, at which thermal degradation starts in the HF/VE composite.

The study demonstrated the potential of UAD in improving machinability of heterogeneous composite materials reinforced with natural fibres. We note that the use of the lathe for the drilling experiments was to impose consistent levels of rotational speed and feed rate. A use of a top-down drill should not affect the obtained results, as shown from our previous studies.

\section{Acknowledgements}

SOI sincerely acknowledges the funding provided by the Niger-Delta Development Commission of Federal Government, Nigeria (NDDC/DEHSS/2013PGFS/OND/3). The authors thank Dr Alan Meadows for support with ultrasonic machining studies carried out at Loughborough Univeristy.

\section{Reference}

[1] Prabhakaran S, Krishnaraj V, Senthil Kumar M, Zitoune R. Sound and vibration damping properties of flax fiber reinforced composites, Procedia Engineering 97 (2014) 573-581

[2] Netravali AN, Chabba S. Composites get greener. Materials Today 6 (2003) 22-29

[3] Joshi SV, Drzal LT, Mohanty AK, Arora S. Are natural fiber composites environmentally superior to glass fiber reinforced composites? Composites: Part A 35 (2004) 371-376

[4] Bledzki AK, Gassan J. Composites reinforced with cellulose based fibres. Progress in Polymer Science 24 (1999) 221-274

[5] Pil L, Bensadoun F, Pariset J, Verpoest I. Why are designers fascinated by flax and hemp fibre composites? Composites: Part A 83 (2016) 193-205 
[6] Pickering KL, Aruan Efendy MG, Le TM. A review of recent developments in natural fibre composites and their mechanical performance. Composites: Part A 83 (2016) 98-112

[7] Izani MA. Norul, Paridah MT, Anwar UMK., Mohd Nor MY, H'ng PS. Effects of fiber treatment on morphology, tensile and thermogravimetric analysis of oil palm empty fruit bunches fibers. Composites: Part B 45 (2013) 1251-1257

[8] Lu N, Oza S. A comparative study of the mechanical properties of hemp fiber with virgin and recycled high density polyethylene matrix. Composites: Part B 45 (2013) 1651-1656

[9] Dittenber DB, GangaRao HVS. Critical review of recent publications on use of natural composites in infrastructure. Composites: Part A 43 (2012) 1419-1429

[10] Ku H, Wang H, Pattarachaiyakoop N, Trada M. A review on the tensile properties of natural fiber reinforced polymer composites. Composites: Part B 24 (2011) 856-873

[11] Shubhra QTH, Alam AKMM, Gafur MA, Shamsuddin SM, Khan MA, Saha M, Saha D, Quiyyum MA, Khan JA, Ashaduzzaman Md. Characterisation of plant and animal based natural fibers reinforced polypropylene composites and their comparative study. Fibers and Polymers 11 (2010) 725-731

[12] Beckermann GW, Pickering KL. Engineering and evaluation of hemp fibre reinforced polypropylene composites: Fibre treatment and matrix modification. Composites: Part A 39 (2008) 979-988

[13] Saba N, Jawaid M, Alothman AY, Paridah MT. A review on dynamic mechanical properties of natural fibre reinforced polymer composites. Construction and Building Materials 106 (2016) 149-159 
[14] Panthapulakkal S, Sain M. Injection-molded short hemp fiber/glass fiber-reinforced polypropylene hybrid composites-mechanical, water absorption and thermal properties. Journal of Applied Polymer Science 103 (2006) 2432-2441

[15] Vijayan K, Zitoune R, Davim JP. Drilling of polymer matrix composites. Springer. ISBN:978-3-642-38345-8 (2013)

[16] Babu GD, Babu KS, Gowd BUM. Optimisation of machining parameters in drilling hemp fibre reinforced composites to maximise the tensile strength using design experiments, Indian Journal of Engineering and Material Science 20 (2013) 385 - 390

[17] Ismail SO, Dhakal HN, Dimla E, Beaugrand J, Popov I. Effects of drilling parameters and aspect ratios on delamination and surface roughness of lignocellulosic HFRP composite laminates. Journal of Applied Polymer Science 133(7) (2016) 1-8.

[18] Phadnis VA, Makhdum F, Roy A, Silberschmidt VV. Experimental and numerical investigations in conventional and ultrasonically assisted drilling of CFRP laminate. Procedia CIRP 1 (2012) 455-459

[19] Makhdum F, Phadnis VA, Roy A, Silberschmidt VV. Effect of ultrasonically-assisted drilling on carbon-fibre-reinforced plastics. Journal of Sound and Vibration 333, (2014) 5939-5952.

[20] Hocheng $\mathrm{H}$, Tai NH, Liu CS. Assessment of ultrasonic drilling of C/SiC composite material. Composites: Part A 31 (2000) 133-142

[21] Dhakal HN, Zhang ZY, Richardson MOW. Effect of water absorption on the mechanical properties of hemp fibre reinforced unsaturated polyester composites. Composites Science and Technology 67 (2007) $1674-1683$ 
[22] Tsao CC, Hocheng H. Taguchi analysis of delamination associated with various drill bits in drilling of composite material. International Journal of Machine Tools and Manufacture 44 (2004) 1085-1090

[23] Li R, Hedge P, Shih AJ. High throughput drilling of titanium alloys. International Journal of Machine Tools and Manufacture 47 (2007) 63-74

[24] Zitoune R, Collombet F, Lopez GH. Experimental and analytical study of the influence of HexFit ${ }^{\circledR}$ glass fibre composite manufacturing process on delamination during drilling. International Journal of Machining and Machinability of Materials 3 (2008) 326-342

[25] Muhammad R, Maurotto A, Demiral M, Roy A, Silberschmidt VV. Thermally enhanced ultrasonically assisted machining of Ti alloy. CIRP Journal of Manufacturing Science and Technology 7 (2014) 159-167

[26] Alam K, Hassan E, Bahadur I. Experimental measurements of temperatures in ultrasonically assisted drilling of cortical bone. Biotechnology \& Biotechnological Equipment 29 (2015) 753-757 